\title{
Does insecticide resistance contribute to heterogeneities in malaria transmission in The Gambia?
}

Kevin Ochieng' Opondo 1,2, David Weetman², Musa Jawara' ${ }^{1}$, Mathurin Diatta', Amfaal Fofana', Florence Crombe ${ }^{2}$, Julia Mwesigwa', Umberto D'Alessandro ${ }^{1,3,4}$ and Martin James Donnelly 2,3*(D)

\begin{abstract}
Background: Malaria hotspots, areas with consistently higher than average transmission, may become increasingly common as malaria declines. This phenomenon, currently observed in The Gambia, may be caused by several factors, including some related to the local vectors, whose contribution is poorly understood.

Methods: Using WHO susceptibility bioassays, insecticide resistance status was determined in vector populations sampled from six pairs of villages across The Gambia, each pair contained a low and high prevalence village.

Results: Three vector species were observed (23.5 \% Anopheles arabiensis, 31.2 \% Anopheles gambiae, $43.3 \%$ Anopheles coluzzii and $2.0 \%$ An. coluzzii $\times$ An. gambiae hybrids). Even at a fine scale, significant differences in species composition were detected within village pairs. Resistance to both DDT and deltamethrin was more common in An. gambiae, most markedly in the eastern part of The Gambia and partly attributable to differing frequencies of resistance mutations. The Vgsc-1014F target site mutation was strongly associated with both DDT (OR $=256.7$, (95\% $\mathrm{Cl} 48.6-6374.3, \mathrm{p}<0.001)$ and deltamethrin survival $(\mathrm{OR}=9.14,(95 \% \mathrm{Cl} 4.24-21.4, \mathrm{p}<0.001)$. A second target site mutation, Vgsc-1575Y, which co-occurs with Vgsc-1014F, and a metabolic marker of resistance, Gste2-114T, conferred additional survival benefits to both insecticides. DDT resistance occurred significantly more frequently in villages with high malaria prevalence $(p=0.025)$ though this did not apply to deltamethrin resistance.

Conclusion: Whilst causality of relationships requires further investigation, variation in vector species and insecticide resistance in The Gambia is associated with malaria endemicity; with a notably higher prevalence of infection and insecticide resistance in the east of the country. In areas with heterogeneous malaria transmission, the role of the vector should be investigated to guide malaria control interventions.
\end{abstract}

\section{Background}

Malaria foci, referred to as 'hot spots', have persistently higher transmission rates [1-3] than contiguous areas and pose challenges to malaria control programmes. They may be refractory to conventional malaria control tools and may act as sources of infection to surrounding areas $[4,5]$. As transmission falls, partly in response to control scale-up, [6] heterogeneity in transmission will become more apparent $[7,8]$. Marked heterogeneity in

\footnotetext{
*Correspondence: Martin.Donnelly@lstmed.ac.uk

${ }^{3}$ London School of Hygiene and Tropical Medicine, London, UK

Full list of author information is available at the end of the article
}

transmission has been documented $[9,10]$ even at the village level $[11,12]$, and in areas of overall reduced transmission like The Gambia [13, 14].

Understanding the epidemiological factors that contribute to the emergence and maintenance of these hotspots is crucial for malaria elimination. Human [15-17] and vector behaviour [18, 19], environmental factors [20-23] and their interplay may give an insight into the transmission dynamics in hotspots. Malaria vector species and populations vary in space and time [18], in anthropophily, exophily and endophily [19] and, importantly, in insecticide susceptibility [24]. 
Resistance to available insecticides has been widely reported in malaria vectors [25-31]. Although a causal relationship between insecticide resistance and malaria transmission has not been shown, spatial variation in susceptibility to insecticides is likely to contribute to the observed heterogeneity in malaria transmission [32]. Since mosquitoes resistant to insecticides survive longer than their susceptible counterparts in the presence of an insecticide, they may live long enough [33] to affect malaria transmission [34-36]. Therefore, insecticideresistant vectors may maintain transmission [37] or, where control interventions have been successful, reverse gains $[35,38,39]$.

\section{Malaria in The Gambia}

In The Gambia, malaria transmission has decreased substantially over the last few years and has become increasingly heterogeneous $[6,13,14]$. Malaria transmission follows rainfall, beginning after the onset of the rains and peaking between October and November. Malaria prevalence in children under the age of 5 years is nationally $4-5 \%$, though in some areas between 2 and $15 \%[6,14$, 40]. In the eastern Gambia, cross-sectional survey across all ages in 2012 estimated malaria prevalence at above $30 \%$.

Malaria control, coordinated by the Gambia National Malaria Control Programme (GNMCP), largely employs long-lasting insecticide-treated bed nets (LLINs) and indoor residual spraying (IRS) with DDT [41]. Between 2013 and 2014, the GNMCP carried out a mass LLIN distribution campaign with Permanet ${ }^{\circledR}$. While a crosssectional survey across Gambian villages showed over $90 \%$ bed net use in 2012 [13], the National LLIN usage in children under the age of 5 years stands at $60 \%$ while in pregnant women it is only $40 \%$ [14]. Annual IRS with DDT has been done since 2008 throughout the country except the coastal region where malaria transmission is extremely low. The first-line treatment is artemetherlumefantrine; pregnant women receive sulfadoxinepyrimethamine as intermittent preventive treatment while children 3-59 months old in upper and central river regions (URR and CRR) obtain seasonal malaria chemoprevention with amodiaquine and sulfadoxinepyrimethamine since the 2014 transmission season.

Vector control activities carried out by GNMCP have probably played a major role in reducing transmission [14]. However, these gains may be reversed by insecticide resistance that has been recently observed in The Gambia $[42,43]$. Vector species distribution varies from east to west along the River Gambia [44]. Four malaria vectors, Anopheles gambiae s.s., Anopheles coluzzii, Anopheles arabiensis and Anopheles melas maintain transmission. Anopheles melas is mainly confined to brackish waters near the coastal region but extends up to approximately $200 \mathrm{~km}$ inland during the rainy season [44-46]. During the rainy season, the population of An. gambiae s.s. rises non-uniformly across the country while An. arabiensis and An. coluzzii persist longer into the dry season [44].

The local dynamics of insecticide resistance may be impacted by the spatio-temporal variation in insect vectors [47-49], which can result from different ecological niche preferences $[50,51]$. In scenarios where populations are separated by ecological factors or barriers, different resistance mechanisms may develop as a result of differential selection pressure or the occurrence of different mutations. Nonetheless, occasional gene flow [52] can transfer mutations [53-56] which may rise rapidly in frequency if selected by anthropogenic activity.

As part of a larger study investigating malaria transmission dynamics in The Gambia, the distribution and patterns of phenotypic resistance and mechanisms in $A n$. gambiae s.l. populations was characterized. Specifically, the hypothesis that variation in the intensity of malaria transmission may be linked with variation in insecticide resistance, mediated by differences in species composition and resistance-related mutations was examined.

\section{Methods \\ Study sites}

The study was conducted in The Gambia, a West African country surrounded by Senegal except to the west that borders the Atlantic Ocean. The country is divided into five administrative regions, namely west coast, lower river region-south (LRR-south), lower river regionnorth (LRR-north), central river region (CRR) and upper river region (URR) (Fig. 1). For purposes of this study and the overall study investigating transmission dynamics, URR was subdivided into URR - north and south to form a total of six regions. Six pairs of rural villages, one pair per region, were selected on the basis of malaria prevalence determined by a nationwide cross-sectional survey [13] (Fig. 1). In each pair, the village with the highest prevalence and that with the lowest prevalence were included. For all pairs there was a significant difference in infection prevalence with the exception of villages $G$ and $\mathrm{H}$ in the central river region (Additional file 1: Table S1).

The Gambia has one rainy season from June to October diminishing in November. The mean daily temperature varies between 25 and $40^{\circ} \mathrm{C}$. The country is primarily low lying with seasonal flooding; and is situated in the open and flat woodland Savannah belt and riverine swamps are common towards the western part of the country [44, 57]. The sea mixes with the river and during the rainy season, brackish waters can extend $200 \mathrm{~km}$ upstream. Rice paddies are common on the margins of the river, especially in the CRR. Towards the east, cereal crop 


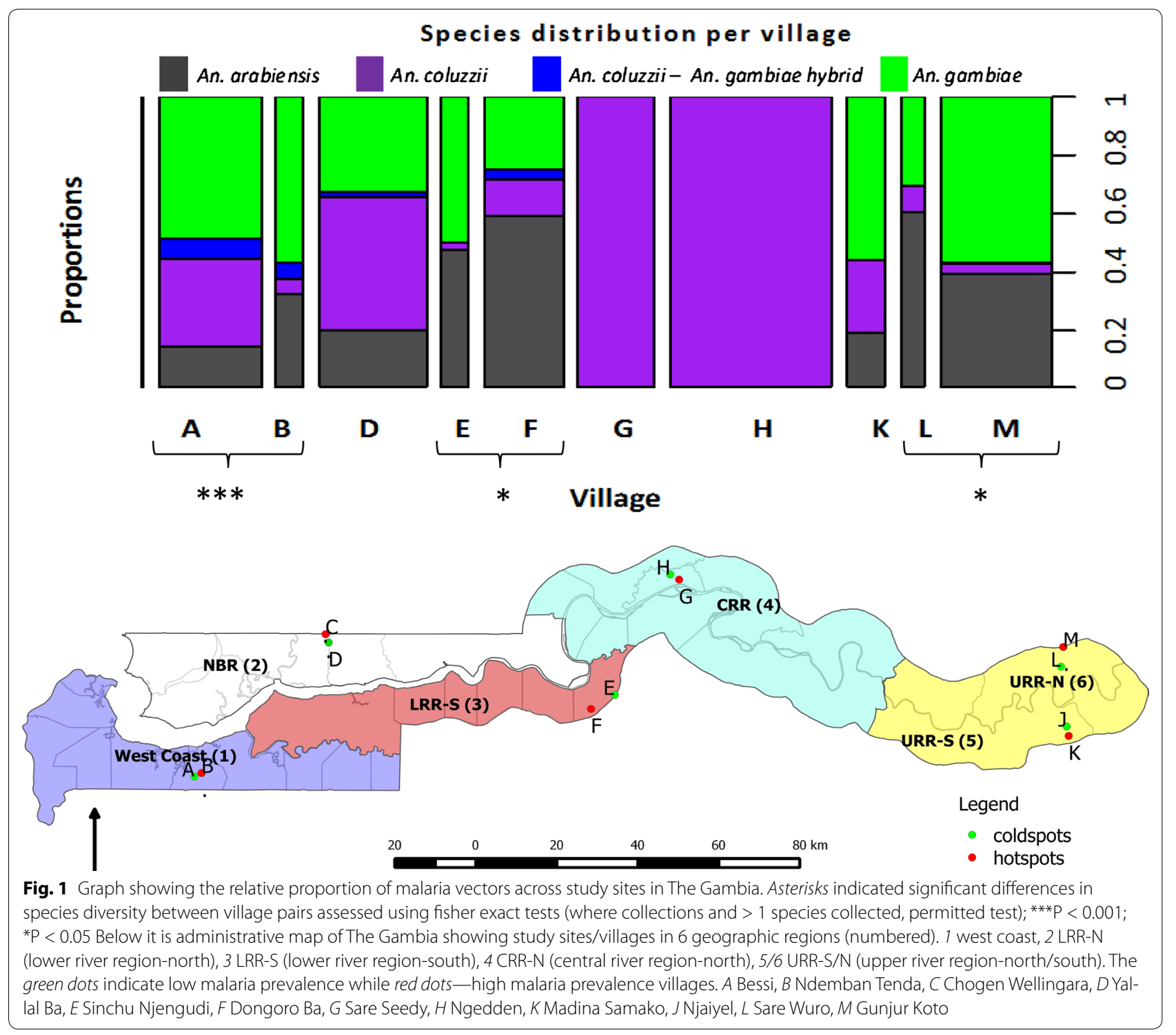

farming is practised. Between the months of June and September 2013, coinciding with mosquito sampling, the GNMCP distributed LLINs and sprayed houses with DDT in the country including all our study villages with the villages in region 2 being sprayed last in the months of September/October.

\section{Study design}

Mosquitoes were sampled between July and October 2013 from the 12 villages. Larval collections were conducted within a $2 \mathrm{~km}$ radius of the centre of the villages and transported to a central insectary in Wali Kunda $\left(13^{\circ} 34^{\prime} \mathrm{N}, 14^{\circ} 55^{\prime} \mathrm{W}\right)$ for rearing and testing. Blood fed adult female collections were performed in villages that had few or no observable breeding habitats. Blood-fed anophelines were transferred to the insectary on the same day of collection where they were kept in individual paper cups containing moistened Whatman filter papers to induce egg laying. The females were also provided with $10 \%$ glucose solution on a cotton wool plug. Eggs from blood-fed mosquitoes from one village were grouped together and allowed to mix randomly.

Mosquitoes, including an insecticide-susceptible colony from Yaoundé, Cameroon, were reared under similar conditions. Larvae were fed on Tetramin ${ }^{\circledR}$ (Tetramin gmbH Germany) fish food and maintained at $28{ }^{\circ} \mathrm{C}$ and $80 \%$ humidity. Upon emergence, adult mosquitoes were provided with $10 \%$ glucose. The WHO protocol [58] on insecticide susceptibility tube assays was used to assay phenotypic resistance. 
Three to five day old mosquitoes in groups of 20-25 were exposed for an hour to either $4 \%$ DDT or $0.05 \%$ deltamethrin impregnated papers [58]. These two insecticides were chosen because the GNMCP distributes deltamethrin-impregnated LLINs $\left(\right.$ Permanet $^{\circledR}$ ) and uses DDT in IRS campaigns. A total of 1005 field collected $A n$. gambiae s.l. were tested. Mortality in the control group (susceptible colony from Yaoundé Cameroon) was always less than $5 \%$. After the phenotypic assays, all mosquitoes tested were stored in $1.5 \mathrm{ml}$ Eppendorf tubes with silica gel and transported to the MRC Fajara for species identification and molecular screening of insecticide resistance loci.

\section{Laboratory processing}

DNA from all mosquitoes was extracted using a Qiagen kit according to manufacturer's protocol. Two polymerase chain reaction protocols $[59,60]$ were used to identify the An. gambiae s.l. to species level. The protocol of Scott et al. was used to identify An. gambiae s.s., An. arabiensis, $A n$. melas while the SINE-PCR [60] protocol was used to further distinguish the An. gambiae s.s., from An. coluzzii and $A n$. arabiensis, simultaneously.

All mosquitoes tested in the insecticide resistance bioassay were genotyped, using TaqMan assays [61-64], for five markers of insecticide resistance, namely the Vgsc$1014 \mathrm{~F}$ and $\mathrm{Vgsc}-1014 \mathrm{~S}$ mutations in the voltage gated sodium channel gene that confer resistance to DDT/ pyrethroids, Vgsc-1575Y which enhances action of the $1014 \mathrm{~F}$ mutation, Gste2-114T which has been associated with metabolic resistance to DDT, and Ace1-119S which is associated with resistance to carbamates and organophosphates [63].

\section{Statistics}

Statistical analysis was done using $\mathrm{R}$ statistical package ( $\mathrm{R}$ version 3.1.2, 2014). Tests of differences in proportions were done to investigate differences in vector populations. Fisher's test was used to determine differences in species composition using an online algorithm. Pearson's Chi squared test for proportions was used to test for differences in mortality between species and villages. Nonparametric tests were used to investigate differences in mortality to insecticides within pairs of study villages and, more generally, geographic variation in insecticide resistance. Differences between individual proportions were assessed using Marascuilo's procedure [65].

Binomial confidence intervals $[66,67]$ were calculated for species distribution and mortality to insecticides. Odds ratios were used to estimate the effect size of DNA marker assays in relation to resistance phenotype. Further, general linear models (GLM) with logit link function for a binomial dependent variable was used to model the effect of different mutations, sampling site, species and interaction between DNA resistance markers on survivorship.

Differences in mortality trend was determined by first grouping villages into three regions, eastern, central and western villages according to ecological zones identified by Caputo et al. [44]. Western villages consisted of A: Bessi, B: Ndemban Tenda, C: Chogen Wellingara and D: Yallal Ba, central villages were E: Sinchu Njengudi, F: Dongoro Ba, G: Sare Seedy and H: Ngedden, and eastern villages were J: Njaiyel, K: Madina Samako, L: Sare Wuro and M: Gunjur Koto.

\section{Ethical clearance}

This study was approved by Medical Research Council Unit (MRC) scientific coordinating committee and ethical clearance obtained from The Gambia Government/ MRC Joint Ethics committee. Informed oral consent was obtained during village sensitization meetings.

\section{Results}

In the 2013 collection season, 1005 mosquitoes were tested using the WHO tube bioassay protocol [58]; 508 against $4 \%$ DDT, 497 against $0.05 \%$ deltamethrin. An. gambiae s.l. was sampled from all but two villages, Madina Samako and Chogen Wellingara (Fig. 2). Three members of the An. gambiae complex were identified: $A n$. gambiae s.s., An. arabiensis, and An coluzzii together with some An. gambiae s.s. x An. coluzzii hybrids (Fig. 1 and Additional file 1: Tables S2, S3, S4). Of the paired study villages, vector composition could only be compared in four pairs because the two remaining pairs lacked mosquitoes in one or both of the constituent villages. In three of the four village pairs, species composition varied between high and low transmission village pairs (Fig. 1).

\section{Phenotypic resistance to DDT and deltamethrin in a WHO bioassay}

There were significant interspecies differences in the $24 \mathrm{~h}$ post-exposure mortality to DDT and deltamethrin. For DDT, resistance was most pronounced in An. gambiae s.s., with only $37 \%$ mortality ( $95 \%$ CI $29-46 \%$ ), compared to the other four species (Pearson Chi squared test, $x^{2}=194, \mathrm{df}=3, \mathrm{p}<0.001$ ) (Fig. 2). Further analysis showed significant differences in mortality except between An. arabiensis and An. coluzzii (Additional file 1: Tables S2, S3, S4). There were also significant differences in mortality between species following deltamethrin exposure (Pearson's Chi squared test, $x^{2}=44.94, \mathrm{df}=3$, $\mathrm{p}<0.001$ ). A significant difference in mortality was only observed when species were compared to An. gambiae s.s., with the exception of An. coluzzii $\times$ An. gambiae s.s hybrids (Additional file 1: Tables S2, S3, S4). 


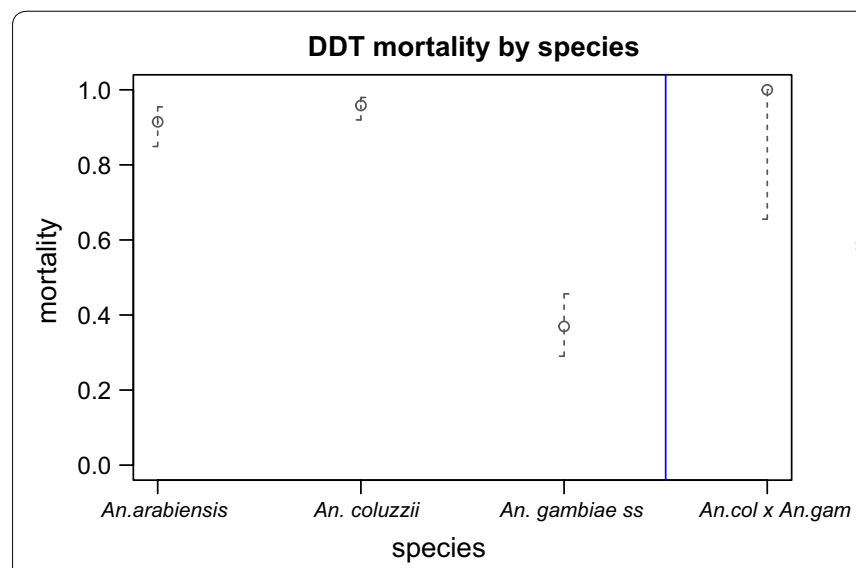

Fig. 2 Species-specific mortality to DDT (left) and deltamethrin (right)

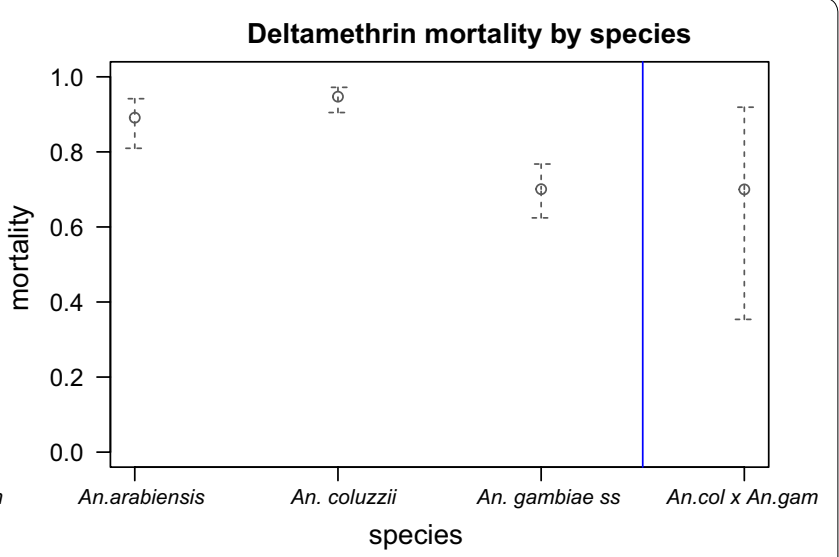

There was a significant correlation between DDT and deltamethrin mortality (Kendall's correlation weighted by village, $\mathrm{\tau}=0.61, \mathrm{p}=0.02$ ), indicating that, An. gambiae s.s. populations were likely to be resistant to both insecticides.

There was variability in inter species mortality within and between villages for deltamethrin $\left(\chi^{2}=9.14\right.$, $\mathrm{p}=0.03)$ and DDT $\left(\mathrm{x}^{2}=7.78, \mathrm{p}=0.05\right)$. An. gambiae s.s. from the east were more resistant than those from the western part of the country (Table 1). DDT mortality tended to decrease from west to east, starting from Sinchu Njengudi (E). For deltamethrin, there was a similar trend though reduced mortality was mainly in Madina Samako (K), Sare Wuro (L) and Gunjur Koto (M) (Fig. 3).

\section{Resistance association of DNA markers}

The frequency of resistance alleles for various markers varied among species, with the Vgsc-1014F mutation being most common in An. gambiae s.s. (Table 2), and

Table 1 Differences in Anopheles gambiae s.l. mortality between east and western populations

\begin{tabular}{|c|c|c|c|c|c|c|}
\hline Insecticide & Species & Region & $\begin{array}{l}\text { Mortality } \\
\text { (\%) }\end{array}$ & $x^{2}$ & Df & $\mathbf{P}$ \\
\hline \multirow[t]{6}{*}{ DDT } & \multirow{2}{*}{$\begin{array}{l}\text { An. gambiae } \\
\text { s.s. }\end{array}$} & East & 6 & \multirow[t]{2}{*}{82.42} & \multirow[t]{2}{*}{1} & \multirow[t]{2}{*}{$<0.001$} \\
\hline & & West & 97 & & & \\
\hline & \multirow[t]{2}{*}{ An. arabiensis } & East & 92 & \multirow[t]{2}{*}{0.11} & \multirow[t]{2}{*}{1} & \multirow[t]{2}{*}{0.74} \\
\hline & & West & 97 & & & \\
\hline & \multirow[t]{2}{*}{ An. coluzzii } & East & 67 & \multirow[t]{2}{*}{4.75} & \multirow[t]{2}{*}{1} & \multirow[t]{2}{*}{0.03} \\
\hline & & West & 94 & & & \\
\hline \multirow{6}{*}{$\begin{array}{l}\text { Deltame- } \\
\text { thrin }\end{array}$} & \multirow{2}{*}{$\begin{array}{l}\text { An. gambiae } \\
\text { s.s. }\end{array}$} & East & 41 & \multirow[t]{2}{*}{32.56} & \multirow[t]{2}{*}{1} & \multirow[t]{2}{*}{$<0.001$} \\
\hline & & West & 86 & & & \\
\hline & \multirow[t]{2}{*}{ An. arabiensis } & East & 97 & \multirow[t]{2}{*}{2.55} & \multirow[t]{2}{*}{1} & \multirow[t]{2}{*}{0.11} \\
\hline & & West & 83 & & & \\
\hline & \multirow[t]{2}{*}{ An. coluzzii } & East & 89 & \multirow[t]{2}{*}{0.04} & \multirow[t]{2}{*}{1} & \multirow[t]{2}{*}{0.85} \\
\hline & & West & 97 & & & \\
\hline
\end{tabular}

in this species there was a highly significant association with resistance to both DDT and deltamethrin. It was not possible to conduct these tests on the other species due to the low frequency of the Vgsc- $1014 \mathrm{~F}$ resistance mutation and high mortality.

In An. gambiae s.s., survival of the Gste2-114T carriers was also significantly increased for DDT and (unexpectedly) for deltamethrin (Table 3). For An. coluzzii, there was no significant association between Gste2-114T and DDT resistance although a significant negative effect was observed for deltamethrin (Table 3).

Species, village and Vgsc-1014F explained significant variation in mortalities to both insecticides, though Gste2-114T, Vgsc-1575Y and interactions between markers were not significant (Table 4). Because of the absence of a sufficient number of survivors carrying resistance mutations in other species, other than An. gambiae s.s., interaction between species and markers was not included in the model. A backward stepwise logistic regression therefore excluded Gste2-114T and Vgsc$1575 Y$ in the final model (Additional file 1: Tables S3, S4). All the molecular markers screened in this study played a role in insecticide resistance but their effect was masked by the presence of the $V g s c-1014 F$ mutation in captured An. gambiae s.s. which was a strong predictor of insecticide resistance.

\section{Insecticide resistance and malaria transmission}

For An. gambiae s.s., mortality to DDT and deltamethrin was compared between high and low malaria prevalence villages. Data from the only village pair where there was no apparent difference in malaria infection rates ( $\mathrm{p}=0.08$; villages $\mathrm{G}$ and $\mathrm{H}$, central river region) are excluded as An. coluzzii was the only species collected. The unpaired Wilcoxon sum rank test was used because some villages did not have mortality data. DDT mortality 

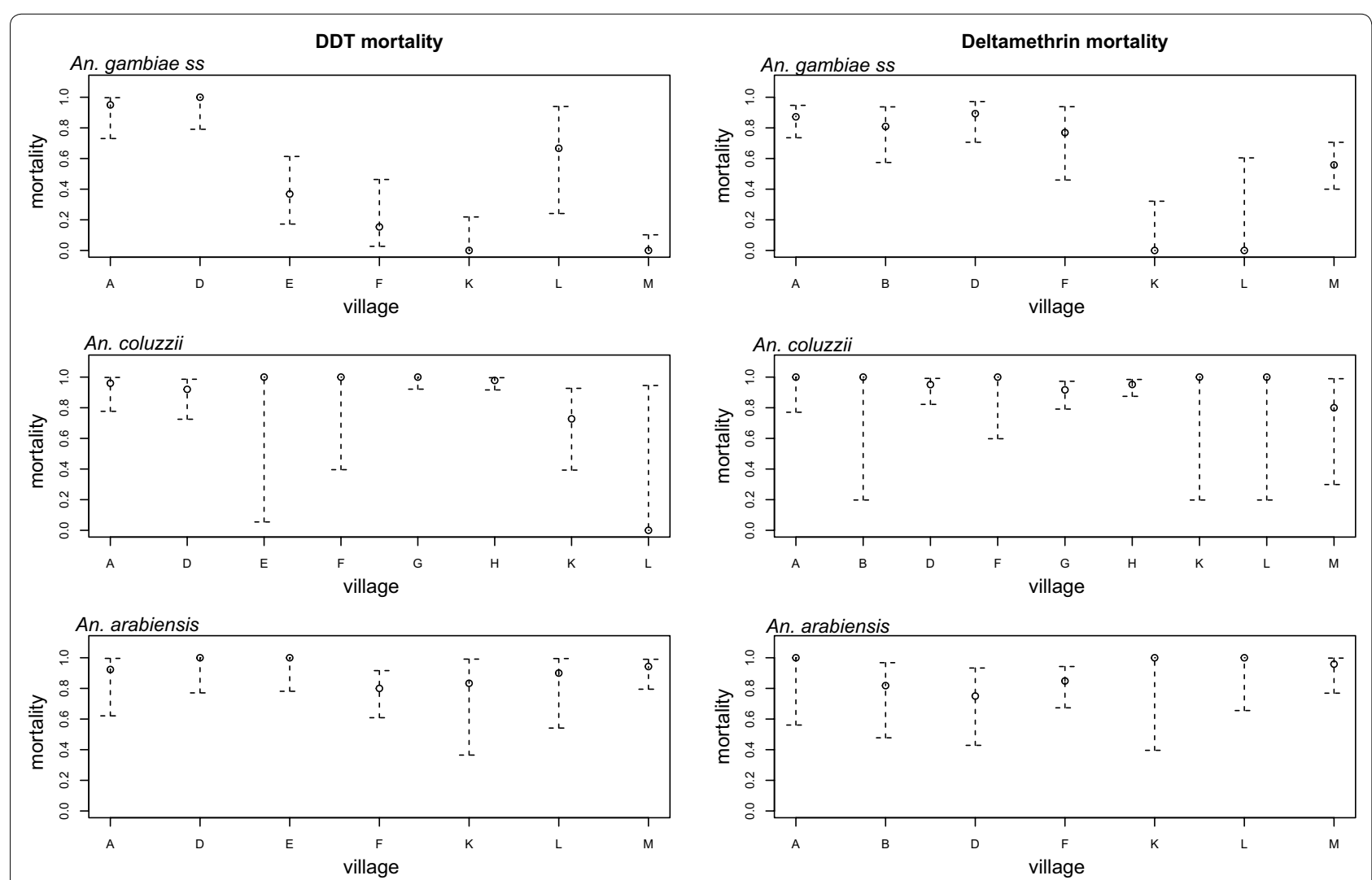

Fig. 3 Mortality by species and village (sampling site). Mortality against DDT (left), mortality against deltamethrin (right). Villages are labelled as in Fig. 1

Table 2 Allele frequency, in percentage expressed as proportions (allele/total number of alleles), of insecticide resistance mutations of malaria vectors in The Gambia

\begin{tabular}{|c|c|c|c|c|c|}
\hline Species & Vgsc-1014F & Vgsc-1014S & Vgsc-1575Y & Gste2-114T & Ace1-119S \\
\hline \multicolumn{6}{|c|}{ Allele frequency (with $95 \%$ confidence intervals) of molecular resistance markers by species } \\
\hline An. gambiaes.s. & $0.51(0.45-0.55)$ & $0.004\left(8.56^{-5}-0.01\right)$ & $0.13(0.1-0.16)$ & $0.097(0.075-0.12)$ & $0.003\left(5.68^{-4}-0.01\right)$ \\
\hline An. arabiensis & $0.05(0.02-0.06)$ & $0.14(0.1-0.17)$ & $0.002\left(1.13^{-4}-0.01\right)$ & $0.017(0.008-0.04)$ & $0(0-0.1)$ \\
\hline An. coluzzii & $0.0012\left(6.16^{-5}-7.62^{-3}\right)$ & $0(0-0.01)$ & $0.0012\left(6.16^{-5}-0.01\right)$ & $0.67(0.67-0.74)$ & $0(0-0.01)$ \\
\hline An. coluzzii $\times$ An. gambiae hybrid & $0.15(0.063-0.31)$ & $0(0-0.11)$ & $0.08(0.02-0.22)$ & $0(0-0.11)$ & $0(0-0.11)$ \\
\hline
\end{tabular}

for An. gambiae s.s. was significantly lower in high prevalence than low prevalence villages (Wilcoxon $\mathrm{W}=0$, $\mathrm{p}=0.03)$. There was no observed difference in An. gambiae s.s. mortality to deltamethrin between high and low prevalence villages ( $\mathrm{W}=3.5, \mathrm{p}=0.24$ ) or for any of the other species for both insecticides.

\section{Discussion}

Phenotypic resistance to DDT and deltamethrin was found mainly in An. gambiae s.s. and was more common in eastern Gambia where malaria transmission is higher than in the western regions [13, 68, 69], suggesting a link between insecticide resistance and observed malaria prevalence. Previous studies exploring the association between insecticide resistance and malaria endemicity have produced contrasting results, with some reporting no effect [70-73] while others suggesting otherwise [32]. In neighbouring Senegal [74] and in South Africa [35], following successful malaria control, increasing insecticide resistance coincided with higher incidence of clinical malaria. Nevertheless, proving a causal relationship between insecticide resistance and malaria transmission is extremely difficult [75]. 
Table 3 Odds ratios of An. gambiae s.s. and An. coluzzii mutants surviving an insecticide exposure for each insecticide resistance marker

\begin{tabular}{|c|c|c|c|c|c|c|}
\hline \multirow[t]{2}{*}{ Species } & \multirow[t]{2}{*}{ Insecticide } & \multirow[t]{2}{*}{ Marker } & \multirow[t]{2}{*}{ Odds ratio } & \multicolumn{2}{|c|}{$95 \%$ confidence intervals } & \multirow[t]{2}{*}{$\mathbf{P}$} \\
\hline & & & & Lower & Upper & \\
\hline \multirow[t]{4}{*}{ An. gambiae s.s. } & DDT & Kdr & 253.74 & 48.07 & 6302.05 & $<0.001$ \\
\hline & & Gste2 & 3.4 & 1.43 & 9.18 & 0.01 \\
\hline & Deltamethrin & $\mathrm{Kdr}$ & 8.37 & 3.99 & 18.47 & $<0.001$ \\
\hline & & Gste2 & 3.4 & 1.175 & 10.29 & 0.02 \\
\hline \multirow[t]{2}{*}{ An. coluzzii } & DDT & Gste2 & 1.5 & 0.34 & 11.35 & 0.72 \\
\hline & Deltamethrin & Gste2 & 0.23 & 0.06 & 0.78 & 0.02 \\
\hline
\end{tabular}

Table 4 The effects of village, species and resistance markers on mortality of mosquitoes to DDT and deltamethrin using GLM

\begin{tabular}{lccllc}
\hline Factor & Df & Deviance & $\begin{array}{l}\text { Residual } \\
\text { Df }\end{array}$ & $\begin{array}{l}\text { Residual } \\
\text { deviance }\end{array}$ & P \\
\hline DDT & & & & & \\
Species & 5 & 190.56 & 490 & 331.83 & $<0.001$ \\
Village & 8 & 114.2 & 482 & 217.62 & $<0.001$ \\
Kdr & 5 & 51.04 & 477 & 166.58 & $<0.001$ \\
1575y & 2 & 1.05 & 475 & 165.53 & 0.59 \\
Gste2 & 2 & 1.8 & 473 & 163.73 & 0.41 \\
Kdr:1575Y & 1 & 0.86 & 472 & 162.87 & 0.35 \\
kdr:gste2 & 4 & 4.33 & 468 & 158.55 & 0.36 \\
1575Y:gste2 & 2 & $1.13 \mathrm{E}-08$ & 466 & 158.55 & 1 \\
Deltamethrin & & & & & \\
Species & 5 & 50.46 & 482 & 371.69 & $<0.001$ \\
Village & 8 & 34.45 & 474 & 337.24 & $<0.001$ \\
Kdr & 5 & 28.22 & 469 & 309.02 & $<0.001$ \\
1575y & 2 & 3.13 & 467 & 305.9 & 0.21 \\
Gste2 & 2 & 4.26 & 465 & 301.63 & 0.12 \\
Kdr:1575Y & 1 & 0.09 & 464 & 301.54 & 0.76 \\
Kdr:gste2 & 3 & 4.07 & 461 & 297.47 & 0.25 \\
1575Y:gste2 & 3 & 0.86 & 458 & 296.61 & 0.83 \\
\hline & & & & &
\end{tabular}

Similar to earlier studies $[68,76,77]$, three malaria vectors, namely An. gambiae s.s., An. coluzzii and An. arabiensis, were observed across the country and in different proportions, in addition to a few hybrids of An. gambiae s.s. and An. coluzzii. Anopheles melas, known to breed in brackish water and usually found in western Gambia [44, $45,78]$, was not collected. This may have been due to the rearing methods employed in the insectary.

The extreme interspecific differences observed in insecticide resistance status and frequency of mutations among them suggests that the involvement of insecticide resistance in malaria heterogeneity would be conditional on the vector species composition. This may help explain the differences in insecticide susceptibility estimates reported by two previous studies in eastern Gambia. In one study done in 2010, [43], An gambiae s.l. susceptibility to DDT and pyrethroids was about $90 \%$ while in 2011 in a village of the same region, susceptibility to the same insecticides was only $50 \%$ [42]. Such differences may be explained by the composition of the mosquito population tested. Indeed, in 2010, $70 \%$ of all anophelines were An. arabiensis, while in 2011 this species represented only $42 \%$ of all mosquitoes tested. Therefore, the high proportion of An. arabiensis may have concealed resistance in An. gambiae s.s.

\section{Mechanisms of resistance}

In An. gambiae s.s., there was a clear association between the $V g s c-1014 F$ mutation and phenotypic resistance, indicating that in The Gambia this is a very effective predictor of DDT and pyrethroids resistance. The Vgsc-1575Y and Gste2-114T markers had modest effects in conferring phenotypic resistance. Though in An. gambiae s.s and An. arabiensis the Vgsc-1014S mutation did not seem to be linked to phenotypic resistance, its low frequency limited statistical power. As in Uganda [79], few samples had both serine and phenylalanine mutations though carriers were also resistant to DDT. Given the low frequency of cooccurrence, it is not possible to establish whether carriage of both mutations confer an advantage, though this may be the case, at least compared to serine alone [80].

\section{Population subdivision}

The different insecticide resistance profile between eastern and western Gambia raises important questions about the drivers and stability of this heterogeneity. The GNMCP has distributed LLINs across the country since 2003 and sprayed houses yearly with DDT since 2008 [14], though only intermittently in the urban west coast region because of the lower malaria transmission. IRS has been carried out in all study villages so that DDT selection pressure should have been uniform. Nevertheless, intense DDT use in a community trial investigating the additional benefits of IRS with DDT to LLIN may have increased insecticide resistance pressure [43, 81]. 
With no history of carbamate and/or organophosphate use for public health in The Gambia, it is interesting to note that the two mosquitoes that had a carbamate/ organophosphate resistance allele, Ace1-119S, were sampled from a village that is approximately $70 \mathrm{~km}$ from Guinguineo district, Senegal, where resistance to bendiocarb has been reported [82, 83], (President's Malaria Initiative, Senegal Report, unpublished), possibly linked to intense IRS campaigns with bendiocarb between 2008 and 2013. Investigation on the genetic connectivity between Gambian and Senegalese An. gambiae populations is currently underway.

Host seeking/foraging and resting behaviour of mosquitoes have been shown to play a role in the development of insecticide resistance [84, 85]. In The Gambia, the lack of detailed information on the behaviour of the sympatric malaria vectors limits proper insights into the causes of resistance in the eastern populations. Endophagy of An. gambiae s.s. may increase their exposure to insecticides, favouring the development of resistance [86, 87]. Conversely, exophagy of $A n$. arabiensis [77] could play a role in the low levels of resistance observed in this species. However, in Senegal, where no difference in biting and host seeking behaviour were found [88] until recently [89], resistance has been reported mainly in An. gambiae s.s. and to a lesser extent in An. arabiensis and An. coluzzii [24, 89].

\section{Conclusion}

Insecticide resistance, which varies by species, seems to be associated to malaria endemicity although other factors not studied here may also be involved. Indeed, in eastern Gambia both insecticide resistance and malaria transmission are higher than in the rest of the country. The vector population is also extremely heterogeneous, underpinning the need for national malaria control programmes to continually monitor, as extensively as possible, the status of insecticide resistance to guide malaria control practices.

\section{Additional file}

Additional file 1: Table S1. Comparison of malaria prevalence rates between villages. Table $\mathbf{S 2}, \mathbf{S 3}, \mathbf{S 4}$. Statistical analysis of species specific mortality to DDT and deltamethrin.

\section{Authors' contributions}

KOO designed and conducted the study, performed laboratory work, analysed the data and wrote the manuscript; DW designed the study, assisted in data analysis, reviewed results and draft manuscripts including final version; MJ, $\mathrm{MD}, \mathrm{AF}$ and FC assisted in coordinating field collection, rearing of samples, molecular laboratory work and reviewed the manuscript; JM assisted in coordinating field activities and reviewed the manuscript; UD, MJD designed the study, assisted in data analysis, reviewed results and draft manuscripts and final version of the manuscript for publication. All authors read and approved the final manuscript.

\section{Author details}

${ }_{1}^{1}$ Medical Research Council Unit, PO Box 273, Banjul, The Gambia. ${ }^{2}$ Department of Vector Biology, Liverpool School of Tropical Medicine, Liverpool, UK. ${ }^{3}$ London School of Hygiene and Tropical Medicine, London, UK. ${ }^{4}$ Institute of Tropical Medicine, Antwerp, Belgium.

\section{Acknowledgements}

We thank the leaders and members of the village who willingly allowed us to collect the data. We are very grateful to village assistants who helped us with village navigation to breeding sites. We are grateful to entomology assistants; Saiga Sowe, Ebrima Jawara, Mohamed Ceesay, Musa Camara, Alhergy Mbenga, Buba Fadera, Bakary Maneh, Sainey Ceesay, Lamin Camara and Lamin Jaiteh who helped tremendously in field and insectary activities. Special gratitude to the MRC drivers; the late Musa Badji, Ousman Bah and Abdou Krubally who drove long distances at night to ferry us and mosquito samples. We also acknowledge the terrific support received from the National Malaria Control Programme. We acknowledge the funding source (MRC-UK, DFID and EDCTP2), without whom, this study would not have taken place.

\section{Competing interests}

The authors have declared that they have no competing interests.

\section{Funding source}

This work is jointly funded by the UK Medical Research Council (MRC) and the UK Department for International Development (DFID) under the MRC/DFID Concordat agreement and is also part of the EDCTP2 programme supported by the European Union.

Received: 15 December 2015 Accepted: 1 March 2016

Published online: 15 March 2016

\section{References}

1. Gaudart J, Poudiougou B, Dicko A, Ranque S, Toure O, Sagara I, et al. Space-time clustering of childhood malaria at the household level: a dynamic cohort in a Mali village. BMC Public Health. 2006;6:286.

2. Ernst KC, Adoka SO, Kowuor DO, Wilson ML, John CC. Malaria hotspot areas in a highland Kenya site are consistent in epidemic and non-epidemic years and are associated with ecological factors. Malar J. 2006;5:78.

3. Kreuels B, Kobbe R, Adjei S, Kreuzberg C, von Reden C, Bäter K, et al. Spatial variation of malaria incidence in young children from a geographically homogeneous area with high endemicity. J Infect Dis. 2008;197:85-93.

4. Bejon P, Williams TN, Liljander A, Noor AM, Wambua J, Ogada E, et al. Stable and unstable malaria hotspots in longitudinal cohort studies in Kenya. PLoS Med. 2010;7:e1000304.

5. Macdonald G. The analysis of malaria epidemics. Trop Dis Bull. 1953;50:871.

6. WHO. World Malaria Report 2013. Geneva: World Health Organization. 2013.

7. WHO. Malaria elimination: a field manual for low and moderate endemic countries. Geneva: World Health Organization. 2007.

8. Woolhouse ME, Dye C, Etard J-F, Smith T, Charlwood J, Garnett G, et al. Heterogeneities in the transmission of infectious agents: implications for the design of control programs. Proc Natl Acad Sci USA. 1997;94:338-42.

9. Bousema T, Drakeley C, Gesase S, Hashim R, Magesa S, Mosha F, et al. Identification of hot spots of malaria transmission for targeted malaria control. J Infect Dis. 2010;201:1764-74.

10. Thomas C, Lindsay S. Local-scale variation in malaria infection amongst rural Gambian children estimated by satellite remote sensing. Trans R Soc Trop Med Hyg. 2000;94:159-63.

11. Burkot TR, Graves PM, Paru R, Wirtz RA, Heywood PF. Human malaria transmission studies in the Anopheles punctulatus complex in Papua New Guinea: sporozoite rates, inoculation rates, and sporozoite densities. Am J Trop Med Hyg. 1988;39:135-44.

12. Browne E, Frimpong E, Sievertsen J, Hagen J, Hamelmann C, Dietz K, et al. Malariometric update for the rainforest and savanna of Ashanti region. Ghana. Ann Trop Med Parasitol. 2000;94:15-22. 
13. Mwesigwa J, Okebe J, Affara M, Di Tanna GL, Nwakanma D, Janha O, et al. On-going malaria transmission in The Gambia despite high coverage of control interventions: a nationwide cross-sectional survey. Malar J. 2015;14:314.

14. GNMCP. Malaria Indicator Survey. Banjul: National Malaria Control Programme. 2011.

15. Stoddard ST, Morrison AC, Vazquez-Prokopec GM, Soldan VP, Kochel $\mathrm{T}$, Kitron $U$, et al. The role of human movement in the transmission of vector-borne pathogens. PLoS Negl Trop Dis. 2009;3:e481.

16. Klinkenberg E, McCall P, Wilson MD, Akoto AO, Amerasinghe FP, Bates I, et al. Urban malaria and anaemia in children: a cross-sectional survey in two cities of Ghana. Trop Med Int Health. 2006;11:578-88.

17. Wesolowski A, Eagle N, Tatem AJ, Smith DL, Noor AM, Snow RW, et al. Quantifying the impact of human mobility on malaria. Science. 2012;338:267-70.

18. Smith T, Charlwood J, Takken W, Tanner M, Spiegelhalter D. Mapping the densities of malaria vectors within a single village. Acta Trop. 1995:59:1-18

19. Gillies M. Anopheline mosquitoes: vector behaviour and bionomics. Malaria: principles and practice of malariology. 1988;1:453-85.

20. Midega JT, Smith DL, Olotu A, Mwangangi JM, Nzovu JG, Wambua J, et al. Wind direction and proximity to larval sites determines malaria risk in Kilifi District in Kenya. Nat Comm. 2012;3:674.

21. Klinkenberg E, McCall P, Wilson MD, Amerasinghe FP, Donnelly MJ. Impact of urban agriculture on malaria vectors in Accra, Ghana. Malar J. 2008;7:151.

22. Ijumba JN, Mosha FW, Lindsay SW. Malaria transmission risk variations derived from different agricultural practices in an irrigated area of northern Tanzania. Med Vet Entomol. 2002;16:28-38.

23. Lindsay SW, Jawara M, Paine K, Pinder M, Walraven GEL, Emerson PM. Changes in house design reduce exposure to malaria mosquitoes. Trop Med Int Health. 2003;8:512-7.

24. Santolamazza F, Calzetta M, Etang J, Barrese E, Dia I, Caccone A, et al. Distribution of knock-down resistance mutations in Anopheles gambiae molecular forms in west and west-central Africa. Malar J. 2008;7:e74.

25. Edi CV, Koudou BG, Jones CM, Weetman D, Ranson H. Multiple-insecticide resistance in Anopheles gambiae mosquitoes, Southern Cote d'Ivoire. Emerg Infect Dis. 2012;18:1508.

26. Antonio-Nkondjio C, Fossog BT, Ndo C, Djantio BM, Togouet SZ, AwonoAmbene $\mathrm{P}$, et al. Anopheles gambiae distribution and insecticide resistance in the cities of Douala and Yaounde(Cameroon): influence of urban agriculture and pollution. Malar J. 2011;10:154.

27. Dabire K, Baldet T, Diabate A, Dia I, Costantini C, Cohuet A, et al. Anopheles funestus (Diptera: culicidae) in a humid savannah area of western Burkina Faso: bionomics, insecticide resistance status, and role in malaria transmission. J Med Entomol. 2007;44:990-7.

28. Casimiro S, Coleman M, Hemingway J, Sharp B. Insecticide resistance in Anopheles arabiensis and Anopheles gambiae from Mozambique. J Med Entomol. 2006:43:276-82.

29. Corbel V, N'Guessan R, Brengues C, Chandre F, Djogbenou L, Martin T, et al. Multiple insecticide resistance mechanisms in Anopheles gambiae and Culex quinquefasciatus from Benin, West Africa. Acta Trop. 2007;101:207-16.

30. Coetzee M, van Wyk P, Booman M, Koekemoer LL, Hunt RH. Insecticide resistance in malaria vector mosquitoes in a gold mining town in Ghana and implications for malaria control. Bull Soc Path Exot. 2006;99:400-3.

31. Ochomo E, Bayoh NM, Kamau L, Atieli F, Vulule J, Ouma C, et al. Pyrethroid susceptibility of malaria vectors in four Districts of western Kenya. Parasit Vectors. 2014;7:310-8

32. Zhou G, Afrane YA, Vardo-Zalik AM, Atieli H, Zhong D, Wamae P, et al. Changing patterns of malaria epidemiology between 2002 and 2010 in Western Kenya: the fall and rise of malaria. PLoS ONE. 2011;6:e20318.

33. N'Guessan R, Corbel V, Akogbeto M, Rowland M. Reduced efficacy of insecticide-treated nets and indoor residual spraying for malaria control in pyrethroid resistance area, Benin. Emerg Infect Dis. 2007;13:199-206.

34. Molineaux L, Shidrawi G, Clarke J, Boulzaguet J, Ashkar T. Assessment of insecticidal impact on the malaria mosquito's vectorial capacity, from data on the man-biting rate and age-composition. Bull World Health Organ. 1979;57:265.
35. Hargreaves K, Koekemoer L, Brooke B, Hunt R, Mthembu J, Coetzee M. Anopheles funestus resistant to pyrethroid insecticides in South Africa. Med Vet Entomol. 2000;14:181-9.

36. Garrett-Jones C, Grab B. The assessment of insecticidal impact on the malaria mosquito's vectorial capacity, from data on the proportion of parous females. Bull World Health Organ. 1964;31:71.

37. Busvine J, Pal R. The impact of insecticide-resistance on control of vectors and vector-borne diseases. Bull World Health Organ. 1969;40:731.

38. Busvine JR. Current problems in the control of mosquitoes. Nature. 1978;273:604-7.

39. SAMCP. Kwazulu/Natal Malaria Crisis Progress Report. South Africa: KwaZulu/Natal Department of Health Statistics. 2001.

40. Ceesay SJ, Casals-Pascual C, Nwakanma DC, Walther M, Gomez-Escobar $\mathrm{N}$, Fulford AJ, et al. Continued decline of malaria in The Gambia with implications for elimination. PLOS ONE. 2010;5:e12242.

41. MoH. National Health Policy 2012-2020. In: Welfare MoHaS, editor. Banjul: Ministry of Health and Social Welfare; 2012. p. 22.

42. Tangena J, Adiamoh M, D'Alessandro U, Jarju L, Jawara M, Jeffries D, et al. Alternative treatments for indoor residual spraying for malaria control in a village with pyrethroid-and DDT-resistant vectors in the Gambia. PLoS ONE. 2013;8:e74351.

43. Pinder M, Jawara M, Jarju LB, Salami K, Jeffries D, Adiamoh M, et al. Efficacy of indoor residual spraying with dichlorodiphenyltrichloroethane against malaria in Gambian communities with high usage of long-lasting insecticidal mosquito nets: a cluster-randomised controlled trial. Lancet. 2014;385:1436-46.

44. Caputo B, Nwakanma D, Jawara M, Adiamoh M, Dia I, Konate L, et al. Anopheles gambiae complex along The Gambia river, with particular reference to the molecular forms of An. gambiae s.s. Malar J. 2008;7:182.

45. Majambere S, Fillinger U, Sayer DR, Green C, Lindsay SW. Spatial distribution of mosquito larvae and the potential for targeted larval control in The Gambia. Am J Trop Med Hyg. 2008;79:19-27.

46. Bryan J, Petrarca V, Di Deco M, Coluzzi M. Adult behaviour of members of the Anopheles gambiae complex in the Gambia with special reference to An. melas and its chromosomal variants. Parassitologia. 1986;29:221-49.

47. Reimer L, Tripet F, Slotman M, Spielman A, Fondjo E, Lanzaro G. An unusual distribution of the kdr gene among populations of Anopheles gambiae on the island of Bioko, Equatorial Guinea. Insect Mol Biol. 2005; 14:683-8.

48. Dabiré KR, Diabaté A, Djogbenou L, Ouari A, N'Guessan R, Ouédraogo J-B, et al. Dynamics of multiple insecticide resistance in the malaria vector Anopheles gambiae in a rice growing area in South-Western Burkina Faso. Malar J. 2008;7:188.

49. Djègbè I, Boussari $\mathrm{O}$, Sidick $\mathrm{A}$, Martin $\mathrm{T}$, Ranson $\mathrm{H}$, Chandre $\mathrm{F}$, et al. Dynamics of insecticide resistance in malaria vectors in Benin: first evidence of the presence of L1014S kdr mutation in Anopheles gambiae from West Africa. Malar J. 2011;10:261.

50. Costantini C, Ayala D, Guelbeogo WM, Pombi M, Some CY, Bassole IH, et al. Living at the edge: biogeographic patterns of habitat segregation conform to speciation by niche expansion in Anopheles gambiae. BMC Ecol. 2009;9:16.

51. Gimonneau G, Pombi M, Choisy M, Morand S, Dabiré RK, Simard F. Larval habitat segregation between the molecular forms of the mosquito Anopheles gambiae in a rice field area of Burkina Faso, West Africa. Med Vet Entomol. 2012;26:9-17.

52. Taylor C, Touré YT, Carnahan J, Norris DE, Dolo G, Traoré SF, et al. Gene flow among populations of the malaria vector, Anopheles gambiae, in Mali, West Africa. Genetics. 2001;157:743-50.

53. Clarkson CS, Weetman D, Essandoh J, Yawson AE, Maslen G, Manske M, et al. Adaptive introgression between Anopheles sibling species eliminates a major genomic island but not reproductive isolation. Nat Comm. 2014;5:4248.

54. Weetman D, Wilding CS, Steen K, Pinto J, Donnelly MJ. Gene flowdependent genomic divergence between Anopheles gambiae M and S forms. Mol Biol Evol. 2012;29:279-91.

55. Chandre F, Manguin S, Brengues C, Dossou YJ, Darriet F, Diabate A, et al. Current distribution of a pyrethroid resistance gene $(\mathrm{kdr})$ in Anopheles gambiae complex from west Africa and further evidence for reproductive isolation of the Mopti form. Parassitologia. 1999;41:319-22. 
56. Weill M, Chandre F, Brengues C, Manguin S, Akogbeto M, Pasteur N, et al The kdr mutation occurs in the Mopti form of Anopheles gambiae s.s. through introgression. Insect Mol Biol. 2000;9:451-5.

57. Majambere S, Lindsay SW, Green C, Kandeh B, Fillinger U. Microbial larvicides for malaria control in The Gambia. Malar J. 2007;6:76.

58. WHO. Test procedures for insecticide resistance monitoring in malaria vector mosquitoes. Geneva: World Health Organization. 2013.

59. Scott JA, Brogdon WG, Collins FH. Identification of single specimens of the Anopheles gambiae complex by the Polymerase Chain Reaction. Am J Trop Med Hyg. 1993;49:520-9.

60. Santolamazza F, Mancini E, Simard F, Qi Y, Tu Z, Della Torre A. Insertion polymorphisms of SINE200 retrotransposons within speciation islands of Anopheles gambiae molecular forms. Malar J. 2008;7:163.

61. Bass C, Williamson MS, Wilding CS, Donnelly MJ, Field LM. Identification of the main malaria vectors in the Anopheles gambiae species complex using a TaqMan real-time PCR assay. Malar J. 2007;6:155.

62. Bass C, Nikou D, Vontas J, Williamson MS, Field LM. Development of high-throughput real-time PCR assays for the identification of insensitive acetylcholinesterase (ace-1R) in Anopheles gambiae. Pest Biochem Physiol. 2010;96:80-5.

63. Jones CM, Liyanapathirana M, Agossa FR, Weetman D, Ranson H, Donnelly MJ, et al. Footprints of positive selection associated with a mutation (N1575Y) in the voltage-gated sodium channel of Anopheles gambiae. Proc Natl Acad Sci USA. 2012;109:6614-9.

64. Mitchell SN, Rigden DJ, Dowd AJ, Lu F, Wilding CS, Weetman D, et al. Metabolic and Target-Site Mechanisms Combine to Confer Strong DDT Resistance in Anopheles gambiae. PLoS ONE. 2014;9:e92662.

65. Marascuilo LA. Large-sample multiple comparisons. Psychol Bull. 1966:65:280.

66. Newcombe RG. Two-sided confidence intervals for the single proportion: comparison of seven methods. Stat Med. 1998;17:857-72.

67. Wilson EB. Probable inference, the law of succession, and statistical inference. J Am Stat Assoc. 1927:22:209-12.

68. Thomson M, d'Alessandro U, Bennett S, Connor S, Langerock P, Jawara $M$, et al. Malaria prevalence is inversely related to vector density in The Gambia, West Africa. Trans R Soc Trop Med Hyg. 1994;88:638-43.

69. Okebe J, Affara M, Correa S, Muhammad AK, Nwakanma D, Drakeley C, et al. School-Based Countrywide Seroprevalence Survey Reveals Spatial Heterogeneity in Malaria Transmission in the Gambia. PLOS ONE. 2014;9:e110926.

70. Henry M-C, Assi S-B, Rogier C, Dossou-Yovo J, Chandre F, Guillet P, et al. Protective efficacy of lambda-cyhalothrin treated nets in Anopheles gambiae pyrethroid resistance areas of Cote d'Ivoire. Am J Trop Med Hyg. 2005;73:859-64

71. Wondji CS, Coleman M, Kleinschmidt I, Mzilahowa T, Irving H, Ndula M, et al. Impact of pyrethroid resistance on operational malaria control in Malawi. Proc Natl Acad Sci USA. 2012;109:19063-70.

72. Tokponnon FT, Ogouyémi AH, Sissinto Y, Sovi A, Gnanguenon V, Cornélie $S$, et al. Impact of long-lasting, insecticidal nets on anaemia and prevalence of Plasmodium falciparum among children under five years in areas with highly resistant malaria vectors. Malar J. 2014;13:76.

73. Lindblade KA, Mwandama D, Mzilahowa T, Steinhardt L, Gimnig J, Shah M, et al. A cohort study of the effectiveness of insecticide-treated bed nets to prevent malaria in an area of moderate pyrethroid resistance, Malawi. Malar J. 2015;14:31.

74. Trape J-F, Tall A, Diagne N, Ndiath O, Ly AB, Faye J, et al. Malaria morbidity and pyrethroid resistance after the introduction of insecticide-treated bednets and artemisinin-based combination therapies: a longitudinal study. Lancet Infect Dis. 2011;11:925-32.

75. Kleinschmidt I, Mnzava AP, Kafy HT, Mbogo C, Bashir Al, Bigoga J, et al. Design of a study to determine the impact of insecticide resistance on malaria vector control: a multi-country investigation. Malar J. 2015;14:282.

76. Jawara M, Pinder M, Drakeley CJ, Nwakanma DC, Jallow E, Bogh C, et al. Dry season ecology of Anopheles gambiae complex mosquitoes in The Gambia. Malar J. 2008;7:9.

77. Lindsay S, Alonso P, Schellenberg JA, Hemingway J, Adiamah J, Shenton $F$, et al. A malaria control trial using insecticide-treated bed nets and targeted chemoprophylaxis in a rural area of The Gambia, west Africa 7. Impact of permethrin-impregnated bed nets on malaria vectors. Trans $R$ Soc Trop Med Hyg. 1993;87(Suppl 2):45-51

78. Bryan J, Di Deco M, Petrarca V, Coluzzi M. Inversion polymorphism and incipient speciation in Anopheles gambiae s.s. in the Gambia, West Africa. Genetica. 1982;59:167-76.

79. Mawejje HD, Wilding CS, Rippon EJ, Hughes A, Weetman D, Donnelly MJ. Insecticide resistance monitoring of field-collected Anopheles gambiae s.l. populations from Jinja, eastern Uganda, identifies high levels of pyrethroid resistance. Med Vet Entomol. 2013;27:276-83.

80. Reimer L, Fondjo E, Patchoke S, Diallo B, Lee Y, Ng A, et al. Relationship between $k d r$ mutation and resistance to pyrethroid and DDT insecticides in natural populations of Anopheles gambiae. J Med Entomol. 2008:45:260-6.

81. Pinder M, Jawara M, Jarju LB, Kandeh B, Jeffries D, Lluberas MF, et al. To assess whether indoor residual spraying can provide additional protection against clinical malaria over current best practice of long-lasting insecticidal mosquito nets in The Gambia: study protocol for a twoarmed cluster-randomised trial. Trials. 2011;12:147.

82. SNMCP. Profil entomologique du paludisme au Senegal: Ministere de la Sante et de la prevention Medicale Profil. 2011.

83. Niang E. A. Variabilité génétique des populations d'Anopheles gambiae s.l. au Sénégal: implications dans le contrôle du paludisme. Cheikh Anta Diop de Dakar. 2014.

84. Padonou G, Sezonlin M, Gbedjissi G, Ayi I, Azondekon R, Djenontin A, et al. Biology of Anopheles gambiae and insecticide resistance: entomological study for a large scale of indoor residual spraying in south east Benin. J Parasitol Vector Biol. 2011;3:59-68.

85. Kloke RG, Nhamahanga $\mathrm{E}$, Hunt RH, Coetzee M. Vectorial status and insecticide resistance of Anopheles funestus from a sugar estate in southern Mozambique. Parasit Vectors. 2011;4:16.

86. Stump AD, Atieli FK, Vulule JM, Besansky NJ. Dynamics of the pyrethroid knockdown resistance allele in western Kenyan populations of Anopheles gambiae in response to insecticide-treated bed net trials. Am J Trop Med Hyg. 2004;70:591-6.

87. de Zulueta J. Insecticide resistance in Anopheles sacharovi. Bull World Health Organ. 1959;20:797.

88. Diatta M, Spiegel A, Lochouarn L, Fontenille D. Similar feeding preferences of Anopheles gambiae and A. arabiensis in Senegal. Trans R Soc Trop Med Hyg. 1998;92:270-2.

89. Ndiath MO, Mazenot C, Sokhna C, Trape JF. How the malaria vector Anopheles gambiae adapts to the use of insecticide-treated nets by African populations. PLoS ONE. 2014;9:e97700.

\section{Submit your next manuscript to BioMed Central and we will help you at every step:}

- We accept pre-submission inquiries

- Our selector tool helps you to find the most relevant journal

- We provide round the clock customer support

- Convenient online submission

- Thorough peer review

- Inclusion in PubMed and all major indexing services

- Maximum visibility for your research

Submit your manuscript at www.biomedcentral.com/submit
() Biomed Central 